\title{
Please Contribute
}

\author{
Jonathan Spencer ${ }^{1}$ and Chris Jackson ${ }^{1}$ \\ 1 \\ Liverpool John Moores University, Graphic Design and Illustration, John Lennon Art \\ and Design Building, 2 Duckinfield St, Liverpool L3 5RD, UK \\ \{j.spencer, c.s.jackson\}@ljmu.ac.uk
}

\begin{abstract}
Please Contribute' is a participatory collective manifesto born in response to the socio-political trend towards oversimplifying the communication of complex concepts. The project chooses to confront this trend and present the complex as complex - to wilfully celebrate complexity itself whilst remaining accessible. Combining elements of indexing and manifesto writing, 'Please Contribute' seeks to engage the reader in a conversation about the society they live in and their relationship to it. This paper documents and explains the genesis, structure and manifestations of the project and considers questions around formats of publication and their implications on audience engagement.
\end{abstract}

Keywords: Manifesto / Participatory / Publication

\section{Introduction}

'Please Contribute' is a participatory collective manifesto born in response to the socio-political trend towards oversimplifying the communication of complex concepts. The project chooses to confront this trend and present the complex as complex - to wilfully celebrate complexity itself whilst remaining accessible.

In the run up to, and in the wake of the Brexit referendum, and with the subsequent UK General Election, we felt we saw a reduction in the quality of social and political debate. Popular dailies such as The Sun, Mail and Express continued their long term eurosceptic and anti-immigration messages. Highly emotive visuals and simplified messages played on age-old fears of the outsider - 'The Other', often employing language and rhetoric that harked back to earlier historical anti-immigration campaigns. False claims such as the now infamous "Let's give our NHS the $£ 350$ million the EU takes every week"[1] on the Brexit Bus were not held to account and left uncontested by the national broadcaster[2].

The referendum ballot paper offered a simple choice to the question "Should the United Kingdom remain a member of the European Union or leave the European 
Union?" The electorate could then cross a box for either "Remain a member of the European Union", or "Leave the European Union".

The question is of course, given the nature of a ballot, a simplistic representation of the choice being given. If we unpack the implications of the question we see that the UK's relationship with the EU impacts on a huge number of areas of our society. Including, but not limited to; immigration, asylum seekers and refugees, economic migrants, trade deals with the EU, trade deals with the rest of the world, security, privacy, law enforcement, sovereignty, jam, pig semen, light bulbs, straight bananas, keeping beaches clean, the air we breathe, animal welfare, saving the bees, health treatment, dealing with pandemics, road safety, offshore tax, corporation tax, firearms, rules on tobacco[3]. Given this level of complexity, perhaps the ballot paper should have instead looked like:
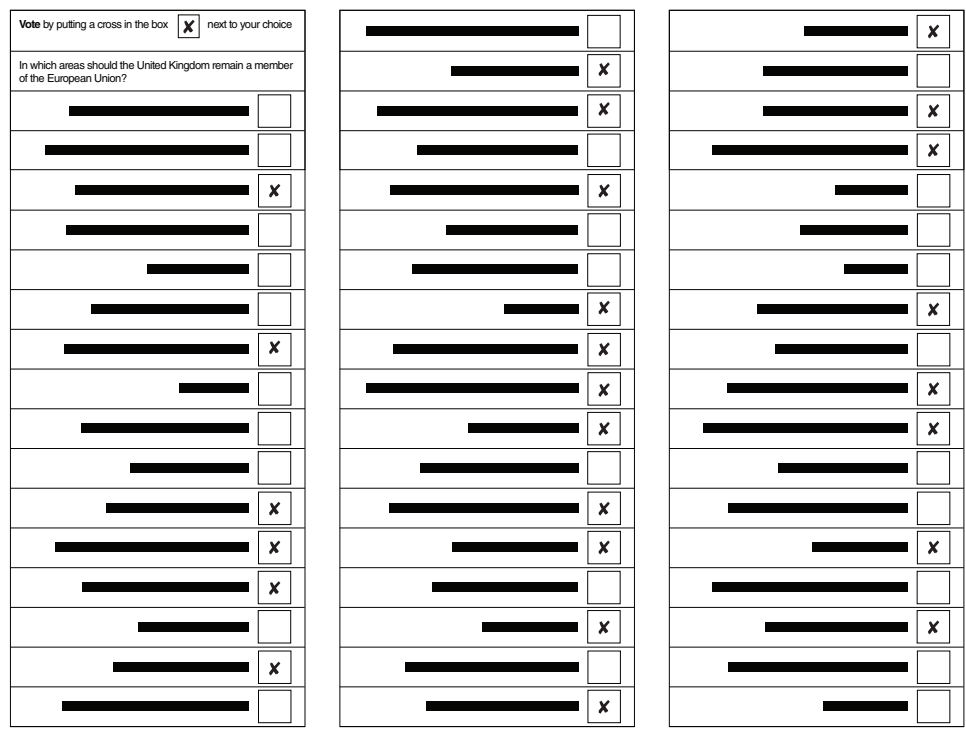

Fig. 1. Proposed EU Referendum ballot.

Rather than a simple yes / no choice it could present a record of preferences, a personal manifesto of sorts. "Yes, I am for straight carrots, but no health regulation or pension provision for expats". An unrealistic proposition, of course, but this is what we felt was missing from the conversation, a sense of the nuanced complexity of these issues.

We were angered at this and concerned with the question of how graphic design might be used to provide a counterpoint to this; to provoke or prompt people into considering their relationship to the society they are a part of? How might we start to explore this? 


\section{The List}

The solution that we arrived at combines two well established processes; indexing, or list making, and the manifesto. There is a long history of manifesto writing, particularly within the political, social and creative spheres. Creating one demands a particular engagement and level of reflective self-analysis with regard to the external world.

The act of list making can be a powerful tool. Whether Samuel Johnson's A Dictionary of the English Language or a simple To-Do list, the process of investigating, selecting, cataloguing, sequencing and publishing provides a methodology to allow us to understand and make sense of the subject matter, imparting a level of control. It creates a positive feedback loop in which the act of creating the index in turn spurs further investigation and analysis. Essentially we, in collaboration with readers of the work, are indexing and presenting a nonhierarchical taxonomy of contemporary society.

\subsection{The Basic Unit}

The premise underpinning the structure is a set of four reflective questions which ask the reader / respondents to assess their own relationship towards a given subject. These were first conceived while Jonathan was studying letterpress under Alan Kitching at the RCA. Seeking an efficient approach to the process, a simple, easily typeset, structure was created which could be repeated to form a larger piece.

The questions deliberately place the reader at the center of the piece starting with a simple binary declaration I am for or I am not for. The option is there to select either, both or neither of these but this is, from our perspective, not important (though it can be revealing), what is important is that the reader considers their relationship to the subject.

The following statements ask the reader to question why they are for or against it; for I am or for I am not. Is it because it impacts or affects their lives, or because it does not? The hope being that the contemplation might prompt further consideration of the importance of this to them.

The audience is asked to redact the statements in order to bring their own voices to the Manifesto. These contributions form strata of information - a record of preferences, concerns and interests. They may be one, or many, layers in depth, and bring a new discourse to the original piece. This collective discussion is also evident in the interactions between the contributors in front of the document itself.

The resulting palimpsestic record provides an insight into the collective mindset of the audience, not just their values but also their interests and understanding 
(including via the reference points not amended). The main aim of the piece is to introduce the audience to a broader range of reference points for consideration and to prompt further debate or investigation.

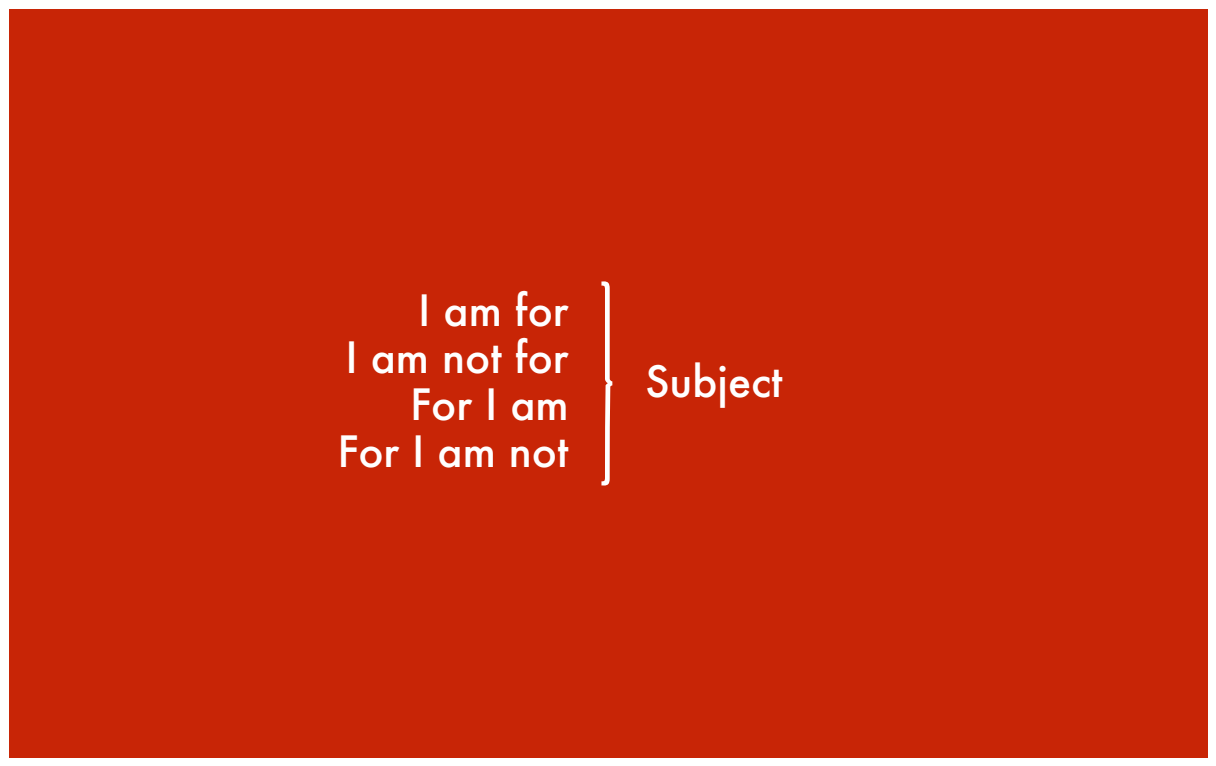

Fig. 2. The Please Contribute Basic Unit.

\subsection{The Structure}

Simple elements, repeated, can yield complexity. The list deliberately repeats the form of the basic unit until it becomes complex, large, and somewhat overwhelming and disorientating. By this it gives the impression that interacting with it will require work. It presents a challenge to the reader while allowing them to revel in the complexity through the process of navigating it.

Although it may initially seem random or disparately arranged, there is an underlying rationale to the order and placement of the units, a deliberate and purposeful structure across the piece.

Firstly, the start is always the same. "ME".

This places the individual at the heart of the experience. Although the project is partly about challenging a movement towards individualism (and away from the collective good), this strategy uses this selfish imperative to prompt introspection. 
This is further reinforced by the redactable statements I am for, For I am, I am not for, For I am not, rather than WE are for, For WE are, WE are not for, For WE are not. This is a deliberate move to place the reader; their relationships with others, their society, and the context of the modern world, as central to the experience.

We then introduce the notion of another:

YOU

followed by THEM, US, WE, encouraging the reader to reflect on their position in relation to others. These are the basic relationships we want to the reader to consider and the building blocks for the rest of the list.

The list moves through various proposals of social order, their implications and structure before introducing forms of governance - the "ocracy" stage. Although this section can change in response to current events, it tends to remain as is from iteration to iteration. The list then presents the reader a larger, more popular culture-centric, continuation of the aggregation, which itself contains discrete structural phases and rhythms. This section is more transient as it concerns itself with contemporary reference points which, by definition, exist in a state of flux.

The intent here is to focus the reader on a basic idea of society, along with a myriad of structural models. Some of these are known, some may not be known but can be understood through research. The aim is to encourage a deeper thinking about the political and social context before exploring the more popular, and recognised, section of the list.

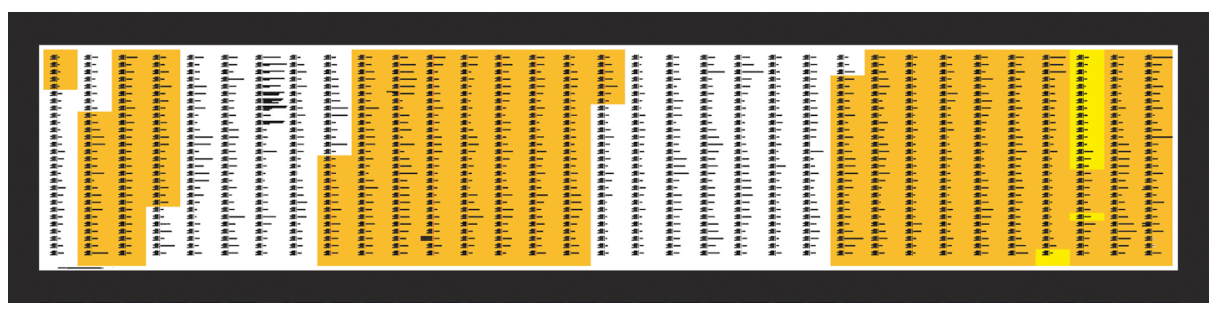

Fig. 3. Highlighted sections in the list.

\subsection{The Format}

Please Contribute exists in a number of formats and acts as a driver for our investigations into methods of publishing and their effect on audience engagement. The core version takes the form of a scroll with other iterations spanning more contemporary forms of publications and installations. 
The scroll was chosen for number of reasons. As one the first easily editable and portable forms of writing they were commonly used to record economic, industrial, religious or cultural information. The nature of this information as well as the historical precedents created by commercial, state and religious institutions lends the format an authority and permanence that others lack. The scale of the scroll, combined with the ability to, at any particular moment, gain an overview of the entirety of the content was also an important consideration. Partitioning the list into the discreet pages of a book introduces unwanted punctuation, structures and associations while diminishing the sense of an overwhelming complexity of information.

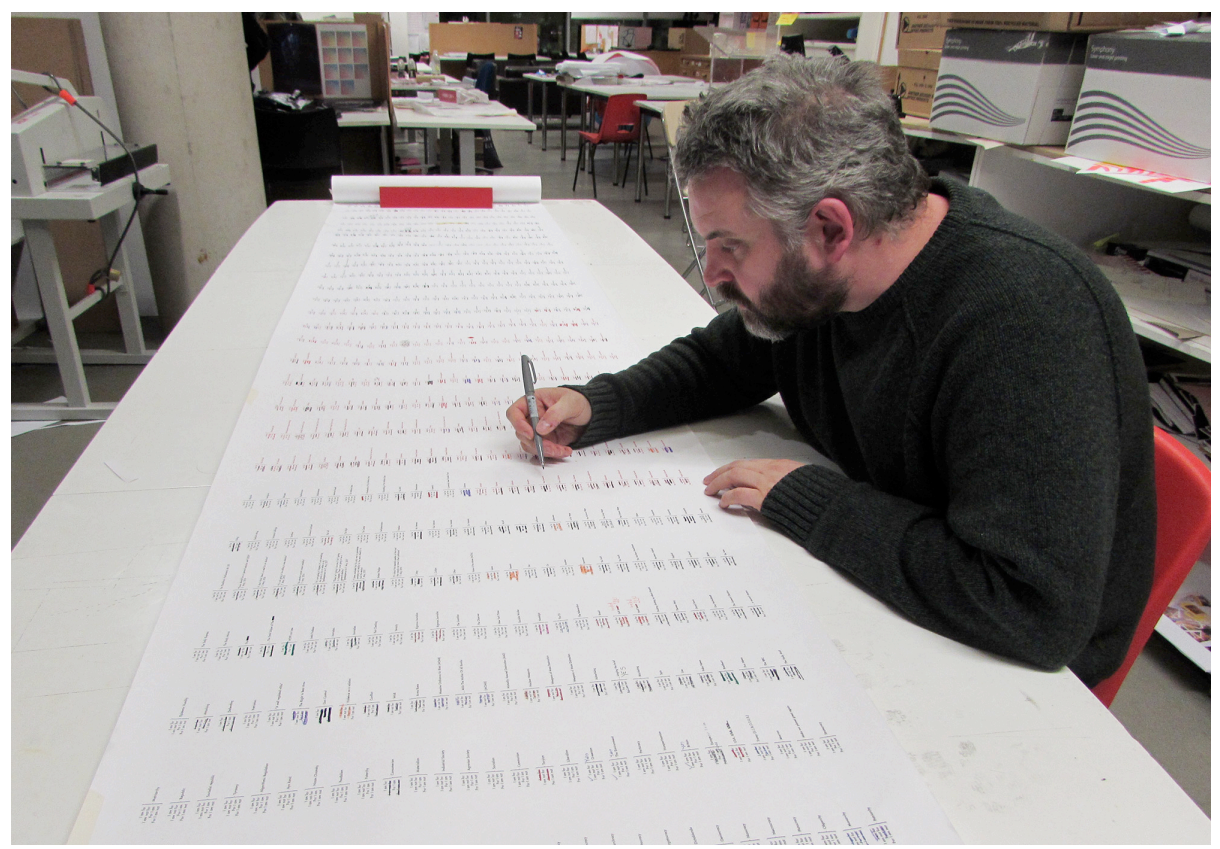

Fig. 4. Jonathan examining the Please Contribute: Kendal scroll.

\section{Please Contribute Iterations}

\subsection{Kendal - 2017}

Presented at a four-day field school exploring potential future directions for arts education with our Graphic Design and Illustration students. The format of this version of the list was a single 3.5-meter scroll with a bespoke education section; the whole totaling 924 defined, and 112 blank user-definable single units. The scroll was visible and accessible throughout the duration. Participation was high with the 
majority of units interacted with at least once. The scroll revealed some unexpected interactions, both with the list as well as between the participants. Issues were debated on the list itself, forming a palimpsestic record of the debate. Some of these were more contentious than others; Coldplay proving particularly divisive.

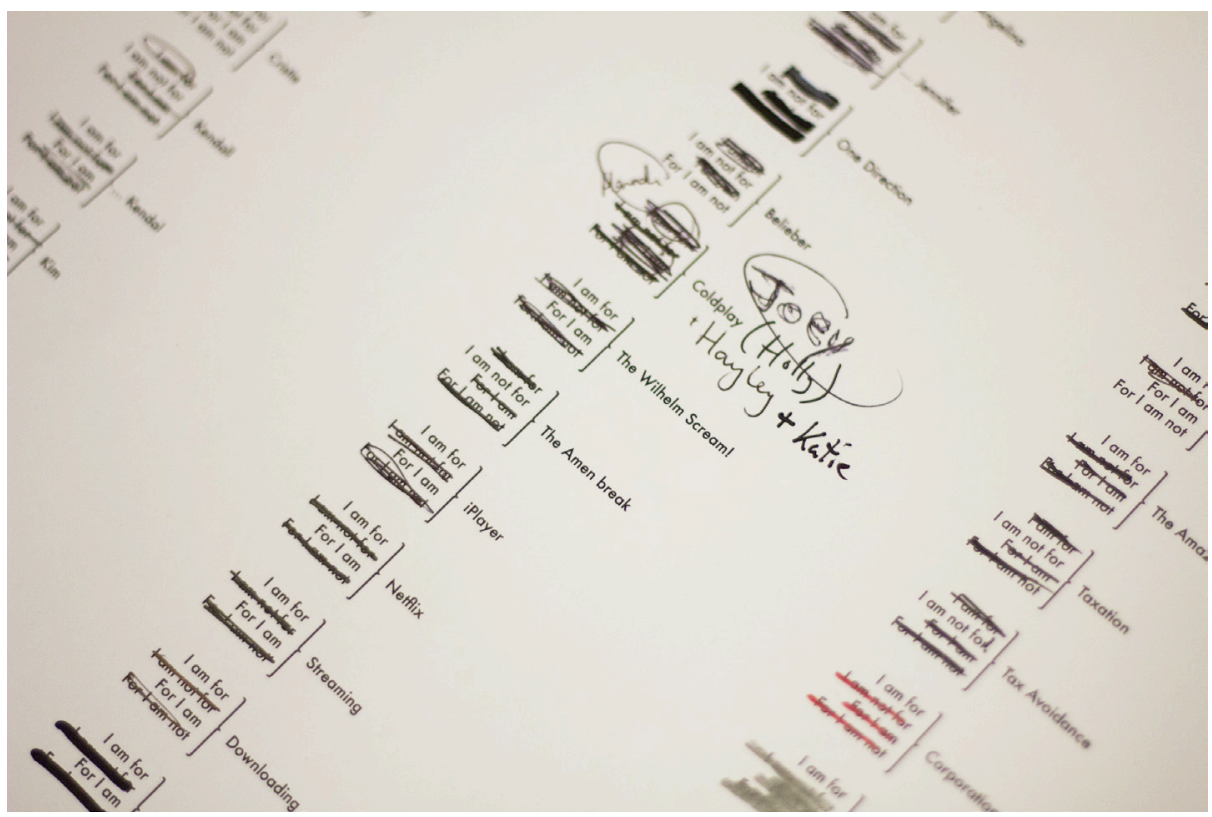

Fig. 5. Please Contribute: Kendal Coldplay debate.

\subsection{Ride Your Pony, Islington Mill / JLADA - 2017/18}

Rather than responding to a list, this version asked the audience to contribute words / units prompted by a single word, 'Britain'. The response to this was mixed, with majority of the respondents submitting fairly frivolous suggestions which offered little to the debate and were often personal jokes. What was interesting though was the creative way in which some of the answers were given. A number of responses used the dotted lines as a divider to suggest paired or opposing units e.g. Traveling $v$ Boundaries. 


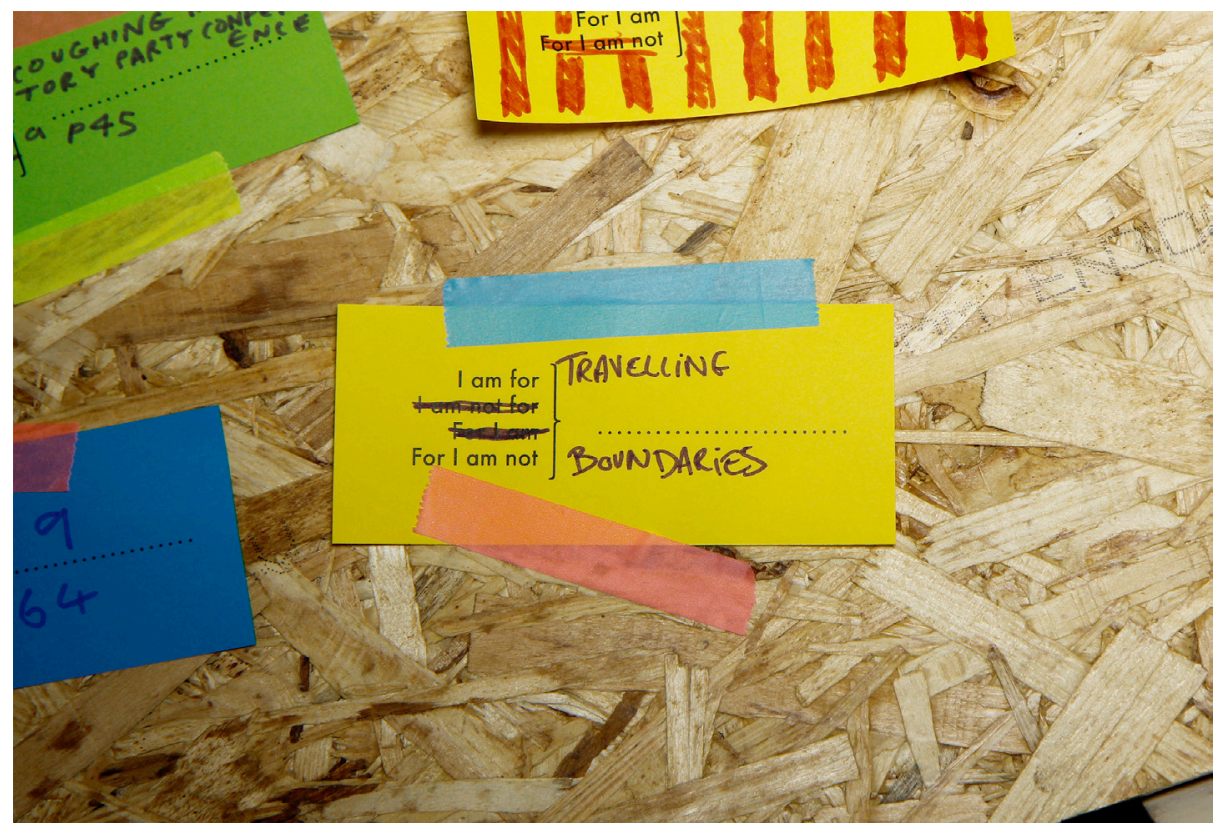

Fig. 6. Submissions at the Ride Your Pony exhibition, Islington Mill, Manchester.

\subsection{CO_two Conference - 2017}

Anticipating that the audience was likely to share a common interest, this iteration took the form of a booklet containing a reduced list themed around the subject of the conference, 'Complexity'. The booklet contained 97 defined units, followed by 36 blank units and from 50 booklets handed out, 12 were completed and returned. As in previous iterations, the nature and format of the responses revealed new ways that people chose to interact with the list. In contrast to previous versions, the section where the reader was invited to contribute their own list was far more considered and coherent. Of the returned booklets, 1 filled all 36 blank units and added 7 additional units in the endpaper, 4 filled all 36, 1 filled 27, 1 filled 11, 1 filled 10, 1 filled 2 and 3 filled no units. It was also encouraging to see the publication prompting delegates of the conference to discuss the various nuances of the list and what they would choose to add to it. 


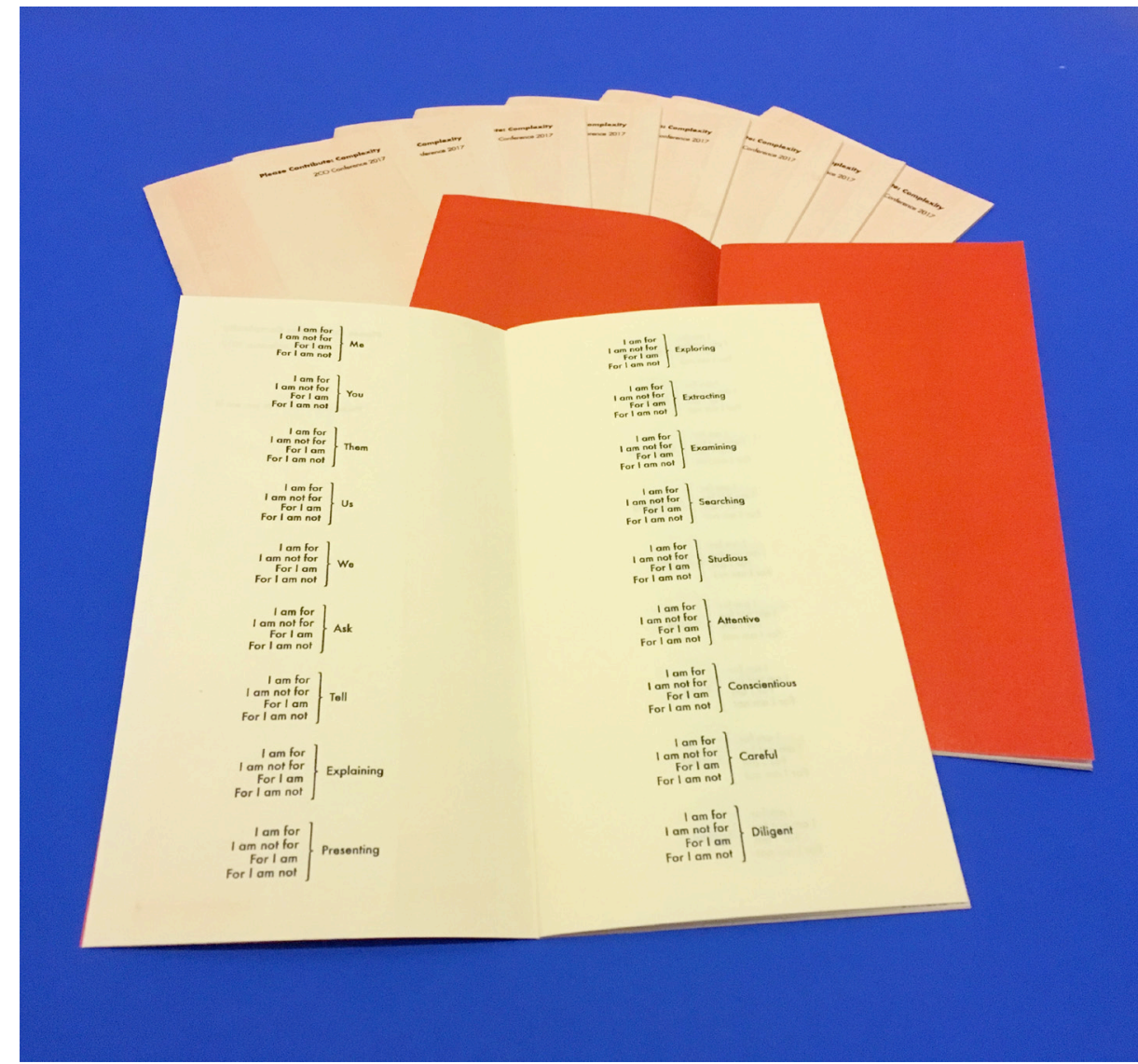

Fig. 7. The Please Contribute: Complexity booklet. Distributed at 2CO_two Conference, Tenerife 2017.

\section{Conclusion}

Please Contribute is proving to be revealing, not just in terms of people's responses to the list, but also in how they choose to interact with it. They are offering new ways to respond and are clearly taking the list seriously. Some of the more obscure words are obviously not being interacted with to any great degree but this itself is not a concern as the idea is not to gather responses on each individual unit but to prompt thought. The better response rates are seen in the redactions and additions to the list itself, as opposed to in the areas for the reader to add their own additional units. While audience, and the context in which the project is encountered affect these rates, it is interesting to note how the method of presenting the information to the reader can influence the quality of response. The booklet format, with its two 
stage approach of presenting units of the list for contemplation, making the reader to take a stance, followed by a request for the reader to construct their own list based on subject areas important to them, seems to be the most effective so far.

Moving forwards, we will continue to explore the relationship between these ongoing iterations and the core list. We will be investigating how we might develop an online implementation, with the concomitant implications for presenting large amounts of information and encouraging user engagement in a digital space. An exhibition "Of Rights and Resistance" at the International Slavery Museum in Liverpool sees another iteration which asks the reader to respond to the articles of the Universal Declaration of Human Rights of 1948 and also to propose their own articles, giving a voice in the creation of their own personal declaration. Please Contribute will continue to present the complexities of the modern age, encourage socially engaged graphic design and challenge the reader to question their role in society and the context in which they live.

\section{References}

[1] Smith, M. (29 March, 2017). Theresa May admits $£ 350$ million pledged to NHS by Brexit campaign isn't going to happen. Mirror. Retrieved from https://www.mirror.co.uk/news/politics/theresa-admits-350-million-pledged10124021

[2] Van Reenen, J. (2016, August). The aftermath of the Brexit vote - the verdict from a derided expert. Retrieved from: http://blogs.Ise.ac.uk/politicsandpolicy/theaftermath-of-the-brexit-vote-a-verdict-from-those-of-those-experts-were-notsupposed-to-listen-to/

[3] Fox, K. Vonberg, J. Dewan, A. (Mar 29, 2017). Brexit: 50 things the UK needs to do after triggering Article 50. CNN. Retrieved from: https://edition.cnn.com/2017/03/29/europe/brexit-article-50-to-dolist/index.html 